\title{
Grandparent Effects on Educational Outcomes: A Systematic Review
}

\author{
Lewis R. Anderson, Paula Sheppard, Christiaan W. S. Monden \\ University of Oxford
}

Abstract: Are educational outcomes subject to a "grandparent effect"? We comprehensively and critically review the growing literature on this question. Fifty-eight percent of 69 analyses report that grandparents' (G1) socioeconomic characteristics are associated with children's (G3) educational outcomes, independently of the characteristics of parents (G2). This is not clearly patterned by study characteristics, except sample size. The median ratio of $\mathrm{G} 2: \mathrm{G} 1$ strength of association with outcomes is 4.1, implying that grandparents matter around a quarter as much as parents for education. On average, 30 percent of the bivariate $\mathrm{G} 1-\mathrm{G} 3$ association remains once $\mathrm{G} 2$ information is included. Grandparents appear to be especially important where $\mathrm{G} 2$ socioeconomic resources are low, supporting the compensation hypothesis. We further discuss whether particular grandparents matter, the role of assortative mating, and the hypothesis that G1-G3 associations should be stronger where there is (more) G1-G3 contact, for which repeated null findings are reported. We recommend that measures of social origin include information on grandparents.

Keywords: grandparents; education; multigenerational mobility; social mobility; social stratification; intergenerational transmission

Citation: Anderson, Lewis R., Paula Sheppard, and Christiaan W. S. Monden. 2018. "Grandparent Effects on Educational Outcomes: A Systematic Review." Sociological Science 5: 114-142.

Received: November 3, 2017

Accepted: January 6, 2018

Published: February 21, 2018

Editor(s): Jesper Sørensen, Kim Weeden

DOI: $10.15195 / \mathrm{v} 5.26$

Copyright: (C) 2018 The Author(s). This open-access article has been published under a Creative Commons Attribution License, which allows unrestricted use, distribution and reproduction, in any form, as long as the original author and source have been credited. @()
THIS article reviews the fast-growing (Figure 1) set of analyses that test, either incidentally or as a primary focus, whether there is an independent association between grandparent (generation 1 or G1) socioeconomic characteristics and grandchild (G3) educational outcomes, independent of the socioeconomic characteristics of the parental generation (G2). As a shorthand we term such an association a "grandparent effect." We aim to identify and extract findings from all such analyses, asking whether each finds a significant, independent G1-G3 association; how large it is relative to the G2-G3 association; and how much of the bivariate G1G3 association is accounted for by adding controls including G2 characteristics. This is important because social mobility-or conversely, the persistence of social status-is conventionally estimated using data on two generations. If grandparents matter for the educational outcomes of their grandchildren, conventional estimates may substantially overestimate the degree of social mobility and provide a skewed picture of equality of opportunity in a society. A systematic review of the evidence is needed now that the literature extends to 69 such analyses for educational outcomes alone (the 40 publications in which these are reported are listed in the online supplement). Moreover, incorporating another generation into stratification research throws up a host of complications and further questions. We aim to shed some light by comprehensively surveying the field.

In the next section we add further background and motivation for this article. We then describe the methods of our systematic literature search and review; present 


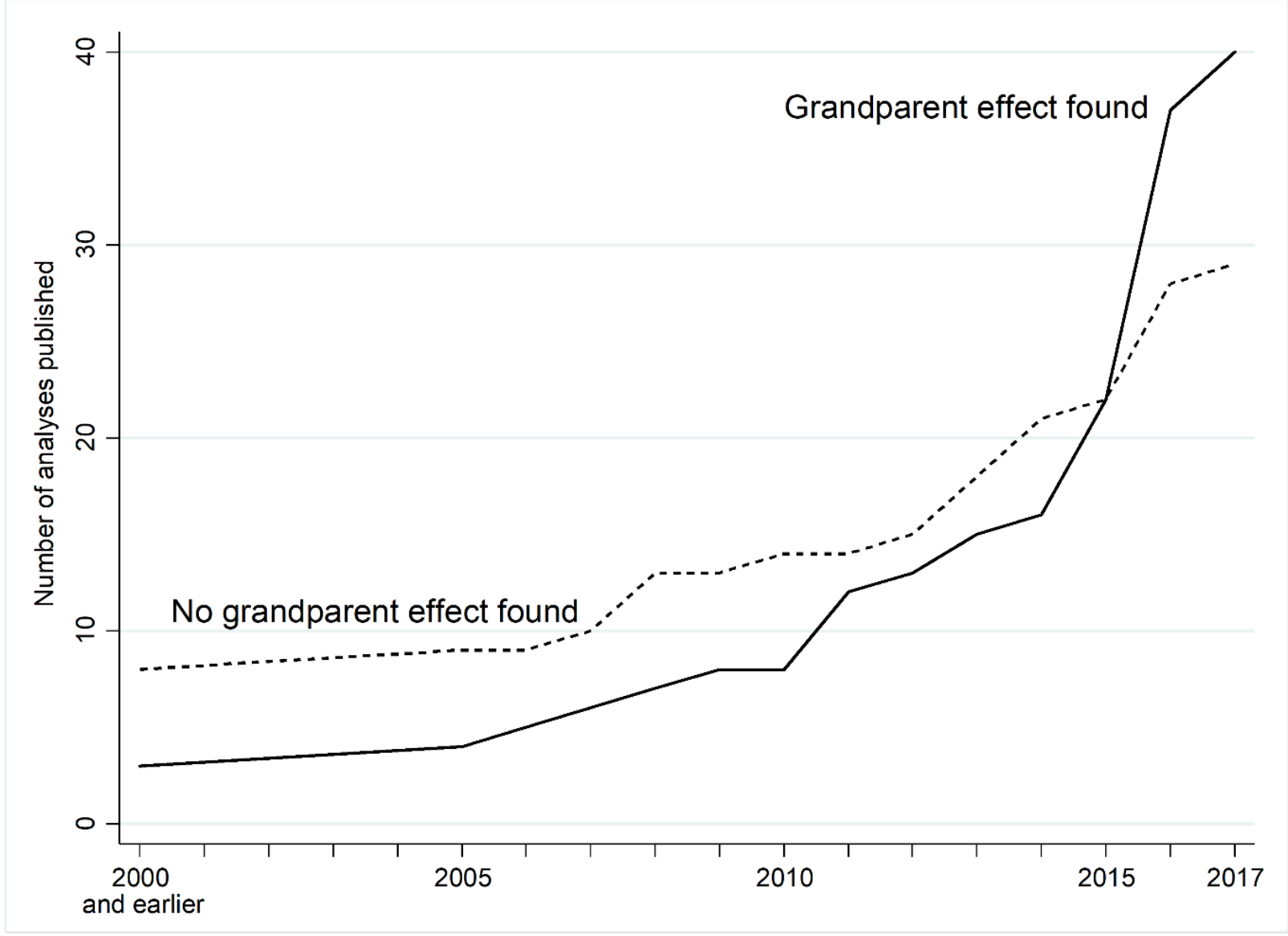

Figure 1: Analyses testing for a grandparent effect (significant association between grandparent characteristics and grandchild educational outcomes, independent of parental characteristics). $N=69$.

results, both quantitative and narrative, with accompanying discussion; and end by offering conclusions and directions for future research.

\section{Background}

A long and fruitful tradition in sociology has examined the intergenerational persistence of socioeconomic characteristics. A wide variety of analytical approaches and data sets have been deployed in this enterprise, but the great majority of studies have in common a two-generation approach: for the purposes of determining the influence of family background on an individual's life chances, the former is effectively equated with the characteristics of that individual's parents. This approach makes an implicit assumption about the intergenerational transmission of advantage over successive generations, namely that this long-run process can be adequately described as a series of independent associations between adjacent generations. Thus, insofar as grandparents affect the outcomes of their grandchildren, 
this effect is indirect, or Markovian, which is to say that the grandparental effect is fully mediated through the parental generation.

An important recent development in the social sciences has been the increasing availability of data on more than the usual two generations (Song and Campbell 2017). A recurrent finding from these data is that the Markov process envisaged by the two-generation literature overestimates social mobility. That is, taking estimates of the persistence of social status based on two observed generations and extrapolating over three or more generations tends to yield an estimate of this persistence that is lower than an estimate based on three or more actually observed generations. Whereas Becker and Tomes (1986) concluded that "[a]lmost all earnings advantages and disadvantages of ancestors are wiped out in three generations," more recent empirical findings do not bear this out (e.g., Clark 2014; Lindahl et al. 2015; Kroeger and Thompson 2016; Pfeffer and Killewald 2017). Correlations and similar parameters estimating the persistence of educational outcomes over three generations are reported in Supplementary Tables 1 and 2 (online supplement) and tend to range between 0.1 and 0.3 .

The prevailing explanation for the stronger-than-expected persistence of socioeconomic status (SES) across multiple generations is that ancestors more distant than the parental generation directly affect a child's outcomes. That is, their influence is not mediated through intervening generations as in the traditional two-generation approach. As Figure 1 illustrates, research exploring whether this is the case has proliferated recently, especially since Mare (2011) called for a "multigenerational view of inequality," arguing that the processes generating social stratification are unlikely to be fully described by the usual approach of beginning with individuals and looking at their parents as the determinants of their relative positions. Not only does this usual approach miss the question of how successfully individuals are able to reproduce social advantage - a question that requires attention to demographyit misses the possible channels beyond one's most immediate ancestors through which family background influences life chances.

With a focus on educational outcomes, this article examines efforts to answer Mare's call, as well as earlier relevant evidence. That is, we comprehensively and critically review the evidence for a direct effect of grandparental resources or characteristics on grandchildren's educational outcomes. Within this broad survey, we focus on several specific issues. First, given that the majority of analyses report some form of significant G1-G3 association, how robust is this association? It may be, for instance, that apparent direct grandparent effects are due to the omission of dimensions of parental SES that in fact mediate the grandparent effect. We examine whether analysis characteristics such as the level of information available on parental SES are correlated with finding a grandparent effect. Second, how substantively important are grandparent effects? We examine this by comparing their strength of association to that reported for parents. Third, how much of the G1G3 association persists after controls for G2 are introduced? Fourth, what evidence has been reported that sheds light on the mechanisms through which a grandparent effect might act? Fifth, what is the role of assortative mating in accounting for G1G3 associations? Sixth, we examine evidence on the distribution of the grandparent effect, as there are reasons to expect heterogeneity in its operation. We use a mix of 
quantitative and narrative methods to give a broad overview of the evidence whilst also paying attention to consequential particulars.

\section{Methods}

\section{Literature Search}

We restrict the scope of this review to educational outcomes. This restriction keeps the review manageable and the subject matter cohesive. In addition to other standard stratification outcomes such as earnings, occupational status, and class (Mukherjee 1954; Chan and Boliver 2013; Dribe and Helgertz 2016; Knigge 2016), the literature on multigenerational effects extends to the intergenerational transmission of fertility outcomes (Kolk 2014), longevity (Piraino et al. 2014), and body mass index (Modin and Fritzell 2009). These fall outside the scope of this review.

To identify relevant studies, in addition to our initial knowledge of the literature, a database search was conducted, and forward and backward reference searching were also employed. ${ }^{1}$ We searched Web of Science (using the "All Databases" option) with the following search terms:

(multigeneration* OR "multiple generations" OR grand-parent* OR grandparent* OR great-grandparent* OR grandfather* OR grand-father* OR great-grandfather* OR grandmother* OR grand-mother* OR great-grandmother* OR "three generations" OR "four generations" OR lineage*)

\section{AND}

(socioeconomic OR socio-economic OR "status attainment" OR "social mobility" OR "social class" OR "class mobility" OR education* OR schooling OR occupation* OR income* OR inequalit* OR earning* OR wealth OR stratification OR "human capital")

Studies were included if they contained any analysis estimating a main effect of grandparental resources or characteristics (of any kind) on grandchildren's educational outcomes whilst also controlling for socioeconomic characteristics in the parental generation.

\section{Data Extraction}

The unit of analysis in this review is what we have termed an analysis. This is distinct from a study (or publication). A study may contain one or more analyses. Separate analyses within a study are distinguished (only) by outcome, population, or both together. Rather than trying to aggregate results at the level of the study, we find it is more meaningful to present results for different outcomes and/or populations as distinct data points (see, e.g., Ziefle 2016). 
A distinct analysis within a study is defined by the presence of any of (1) a distinct outcome measure, (2) a distinct population, or (3) a distinct combination of outcome and population. However, the most aggregated analyses available are used from each study. For instance, if results are reported for men, women, and for the full sample, the only analysis taken from the study is the full sample analysis. Populations are regarded as distinct if they differ according to country, cohort, sex of the grandchild, or set of three generations (i.e., in a study with data on four generations, a G1-G3 analysis is regarded as distinct from a G2-G4 analysis). For example, the study by Lindahl et al. (2015) contains three analyses: one tests for a direct G1-G3 association in years of education, a second does the same for G2-G4, and a third analysis tests a direct G2-G4 association for the outcome of whether the grandchild has completed an academic high school track.

Other changes between samples, measures, or analytic approaches are not regarded as constituting distinct analyses: for example, examining those with data on maternal and paternal grandparents separately (Chiang and Park 2015), reporting estimates first excluding and then including vocational education in the measurement of years of schooling (Braun and Stuhler 2017), or first reporting preliminary regressions and then structural equation models (Warren and Hauser 1995; Grant 2005). Where multiple terms for grandparent resources are included, whether simultaneously (Møllegaard and Jæger 2015) or in separate models (Bol and Kalmijn 2016), this also does not constitute a distinct analysis.

Where a sequence of models is reported for a given analysis, the model with the greatest number of covariates is used (the fullest model). There are two exceptions to this. ${ }^{2}$ First, where interaction terms are introduced, the fullest model prior to the introduction of interactions is used. The descriptive results therefore reflect grandparent associations across whole samples-that is, averaged across the distribution of potentially important moderators. This may of course obscure heterogeneity in G1-G3 associations. Results of analyses including interaction terms are discussed further below. The second exception is that where potential mediators of a grandparent effect that are characteristics of the grandchild are included, the model prior to the inclusion of such terms is used. For instance, Yeung and Conley (2008) introduce a term for the child's self-esteem, which a priori may lie on a causal path from grandparent education to child's educational outcome. In addition, where applicable, we use the results from the model with the greater number of grandparent terms (e.g., a model with a term each for grandfather's and grandmother's education is favored over one with a single term for the education of the most educated grandparent). This is for consistency; sets of results presented with varying operationalizations of G1 characteristics are discussed below.

Lastly, some analyses report results from alternative analytical approaches. Results from structural equation models are favored over regressions, as they are a minor and straightforward extension of the conventional approach. Although we cannot include results from a number of other alternative and more complex models in a straightforward manner in our quantitative review, we discuss these important contributions in the "Alternative Analytical Approaches" section. These alternative approaches include instrumental variable models, marginal structural models, and the use of cousin correlations in outcomes. 


\section{Descriptive Statistics}

Proportions finding an independent G1-G3 association. Each analysis is coded as 0 or 1 for finding a grandparent effect-that is, any independent G1-G3 association significant at the 0.05 level (even if others within an analysis are nonsignificant). We tabulate simple proportions of analyses finding a grandparent effect, showing how this varies according to a range of analysis characteristics that might bias towards or against finding an effect, or in some cases simply reflect genuine heterogeneity in the association. These characteristics are as follows: outcome, country, data set, number of observations, number of grandparents for whom information is available, how (many) grandparent terms are included, how (many) terms are included for the equivalent parental characteristics, and how many additional parental socioeconomic controls are included (i.e., in addition to those that are the equivalent of the grandparent term being tested). Other analysis characteristics are a priori interesting but in fact exhibit little variation-for instance, time period.

The categorization of these analysis characteristics is mostly self-explanatory. We here describe those which may not be. Outcome is categorized as either level (e.g., years of education, whether any tertiary education, choice of high school track) or ability (e.g., reading ability, grade point average, cognitive ability). The two types of outcomes may be subject to different influences because the former involves an element of choice. Observations refers to the number of grandchildren. The "other" category within G1 data availability refers to patterns of availability of data that are each rare (e.g., between one and four grandparents [Ferrie, Massey, and Rothbaum 2016]). For G1 included and G2 included, the category "joint/sum" refers either to the sum of the available (grand)parents' values of a certain resource (e.g., years of education) or to characteristics that pertain to (or are simply measured at the level of) the (grand)parents as a set-for instance, neighborhood poverty (Sharkey and Elwert 2011), family income, or social capital. Because the mean of the parents' values is very rarely used, the categories "mean" and "joint/sum" are grouped together for G2 included. The category "other" for these variables refers to approaches such as including multiple grandparent terms operationalized in different ways, such as each grandparent's years of education and grandparental family income; another example of an "other" approach is entering the number of postsecondary-educated grandfathers into the model (Sheppard and Monden 2017). Parental (or other G2) socioeconomic characteristics that are included in addition to the parental values of the grandparent terms being tested are captured in G2 SES controls included, the simple sum of such variables included in the analysis. Separate variables used in constructing these controls are counted separately even if just one term is included in the model. For instance, if the mean of parents' years of education is included, this is counted as two because it taps both the mother's and father's education. Alternative approaches to coding these additional parental controls yield highly similar results.

Strength of association relative to parents. Differences between the analyses make the effect sizes largely incommensurable in absolute terms. We take an approach that aims at making meaningful comparisons of effect size between analyses. Because the analyses reviewed here almost all control for the precise G2 equivalent of the G1 characteristic being tested, it is in many cases possible to calculate the ratio of 
parental to grandparental effect sizes. This provides a scale-free parameter that can be compared across analyses and itself tabulated, as above, according to analysislevel variation in factors such as which controls are included. Where an analysis tests multiple types of G1 resources, we average across the separate ratios within an analysis.

Attenuation with inclusion of controls. A further parameter of interest is the extent to which a bivariate G1 coefficient is attenuated with the inclusion of the controls that enter into the full model. This reflects the degree to which any G1-G3 association is accounted for by including parental characteristics. Fewer analyses report bivariate G1-G3 associations, as they are often not the focus. Where G1 coefficients are reported that include only relatively minor controls such as birth year or survey year, these estimates are taken as the bivariate baseline for calculating this parameter.

\section{Narrative Review}

Analyses bearing on several further substantively interesting questions are relatively low in number or otherwise do not lend themselves to quantitative analysis. For these we give a narrative review of the results and in some cases use summary tables. We discuss the following: potential mechanisms underlying a direct effect of grandparents, which, following Knigge (2016), we divide into contact-based and non-contact-based; inclusion of both parents and, relatedly, assortative mating of G2 as an indirect mechanism and possible explanation for the grandparent effect; the distribution of grandparent effects-in particular, whether there are nonlinearities and interactions involved; whether there is evidence for particular grandparents being especially important in the transmission of socioeconomic status; whether results are robust to different specifications within analyses; limitations to accurately estimating grandparent effects; and finally, the results of studies taking alternative analytical approaches.

\section{Results}

\section{Proportions Finding an Independent G1-G3 Association}

Figure 2 shows the proportions of analyses finding a grandparent effect across a range of analysis characteristics. Few clear patterns emerge: 58 percent of studies find evidence of a grandparent effect as defined above. This proportion is higher among those looking at ability rather than level outcomes. The proportions appear relatively stable across settings. Whilst certain suggestive patterns are discernible, there is reason to interpret them with caution. For instance, though analyses more often find evidence of a grandparent effect in the United States compared with Germany, direct comparative evidence challenges this. Neidhöfer and Stockhausen (forthcoming), ${ }^{3}$ included here as a single cross-national analysis, find no evidence for a grandparent effect in the United States but do for Germany, whereas Hertel and Groh-Samberg (2014) report that "the pattern of three-generation [social class] mobility is similar in both countries" (p. 35). Similarly, the high figure for Sweden is 

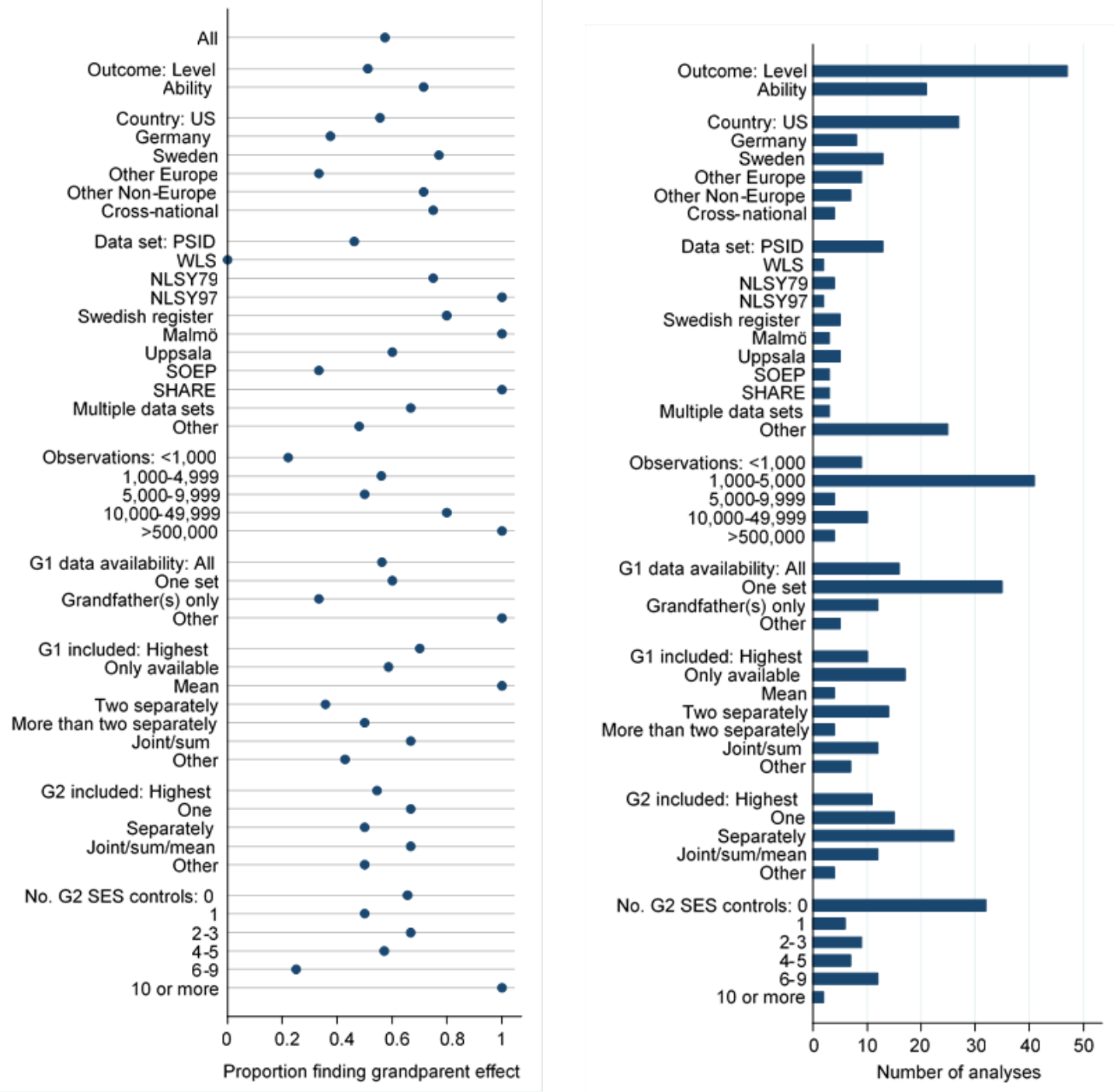

Figure 2: Proportion of analyses finding a grandparent effect (left panel) and number of analyses in each category (right panel). $N=69$. Notes: There are no analyses with the number of observations between 50,000 and 500,000. PSID = Panel Study of Income Dynamics (United States); WLS = Wisconsin Longitudinal Study (United States); NLSY79 = National Longitudinal Survey of Youth 1979 (United States); NLSY97 = National Longitudinal Survey of Youth 1997 (United States); Malmö = Generations Emanating from the Malmö Study (Sweden); Uppsala = Uppsala Birth Cohort Study Multigenerational Database (Sweden); SOEP = German Socio-Economic Panel (Germany); SHARE = The Survey of Health, Ageing and Retirement in Europe (27 European countries and Israel).

likely due partly to the extremely large sample sizes available in register data, which may make even substantially very small grandparent effects statistically significant and thus increase the likelihood of finding a grandparent effect (as reflected in the increasing proportion across the sample size categories here). Different analyses using the same data set often vary in whether or not a grandparent effect is apparent. 
Finding a main effect may then depend on the analytical approach and/or the outcome or grandparental characteristics of interest, but it appears that grandparent effects are not obviously either present or absent within a given sample or setting.

A similar proportion of analyses find a grandparent effect when data are available on all four grandparents as when there are data on just one set of grandparents. This suggests that assortative mating in the parental generation leads to a correlation between the characteristics of an individual's two sets of grandparents, such that having information on one set only-most often all that is available-may not lead to drastically different conclusions. Although the proportion in the other category is high, the number of analyses this represents is so low that the proportion is not likely to be informative.

The proportions finding an effect do not clearly decline with increasing numbers of parental SES controls, as the omitted-variables critique of apparent grandparent effects would imply. Forty-five percent of analyses controlling for four or more parental SES variables (in addition to the parental equivalents of the grandparent characteristics) report finding a grandparent effect, whereas the figure for analyses with no such additional controls is 65 percent.

\section{Strength of Association Relative to Parents}

An advantage of examining the relative strength of association of G1 and G2 with G3 is that the result it is not sensitive to sample size, unlike examining whether a coefficient is significant at the 0.05 level. The pairwise correlation among analyses between finding a significant G1-G3 association and $\log (N)$ is $0.33(p<0.01)$, whereas the G2:G1 strength of association ratio is uncorrelated with sample size: the corresponding $r$ is $0.01(p=0.92)$.

The mean values of this G2:G1 ratio are shown in Figure 3 across the same range of analysis characteristics. A larger number means a smaller G1-G3 association relative to the G2-G3 association. This G2:G1 ratio across the analyses has a mean of 9.10 , a standard deviation of 12.20 , a median of 4.10 , and an interquartile range of 1.58 to 11.71 .

G1 associations appear relatively large for ability outcomes. This may reflect the younger age of the grandchildren in these samples: test scores are amenable measures far earlier than years of completed schooling or whether a child achieves tertiary education. We see ratios below 1 (stronger association with G1 than with G2) in several of these analyses, for outcomes such as verbal comprehension and vocabulary for a sample with a mean age of 5.5 (Hill and O'Neill 1994; Phillips et al. 1998), the Applied Problems component of the Woodcock-Johnson Achievement Test-Revised given to 3- to 5-year-olds (Yeung and Conley 2008), and both reading and maths scores (again derived from Woodcock-Johnson tests) for children aged from 5 to 18 (Sharkey and Elwert 2011). Ferguson and Ready's results imply ratios of 1.20 and 1.21 for maths and literacy skills assessments, respectively, at kindergarten entry (2011). However, there are small ratios at higher ages and vice versa: a figure of 1.58 for 18-year-olds at conscription given a cognitive ability test (Modin and Fritzell 2009) and a figure of 19 for a verbal comprehension outcome for the same sample, with a ratio below 1 for maths (Yeung and Conley 2008). The general 


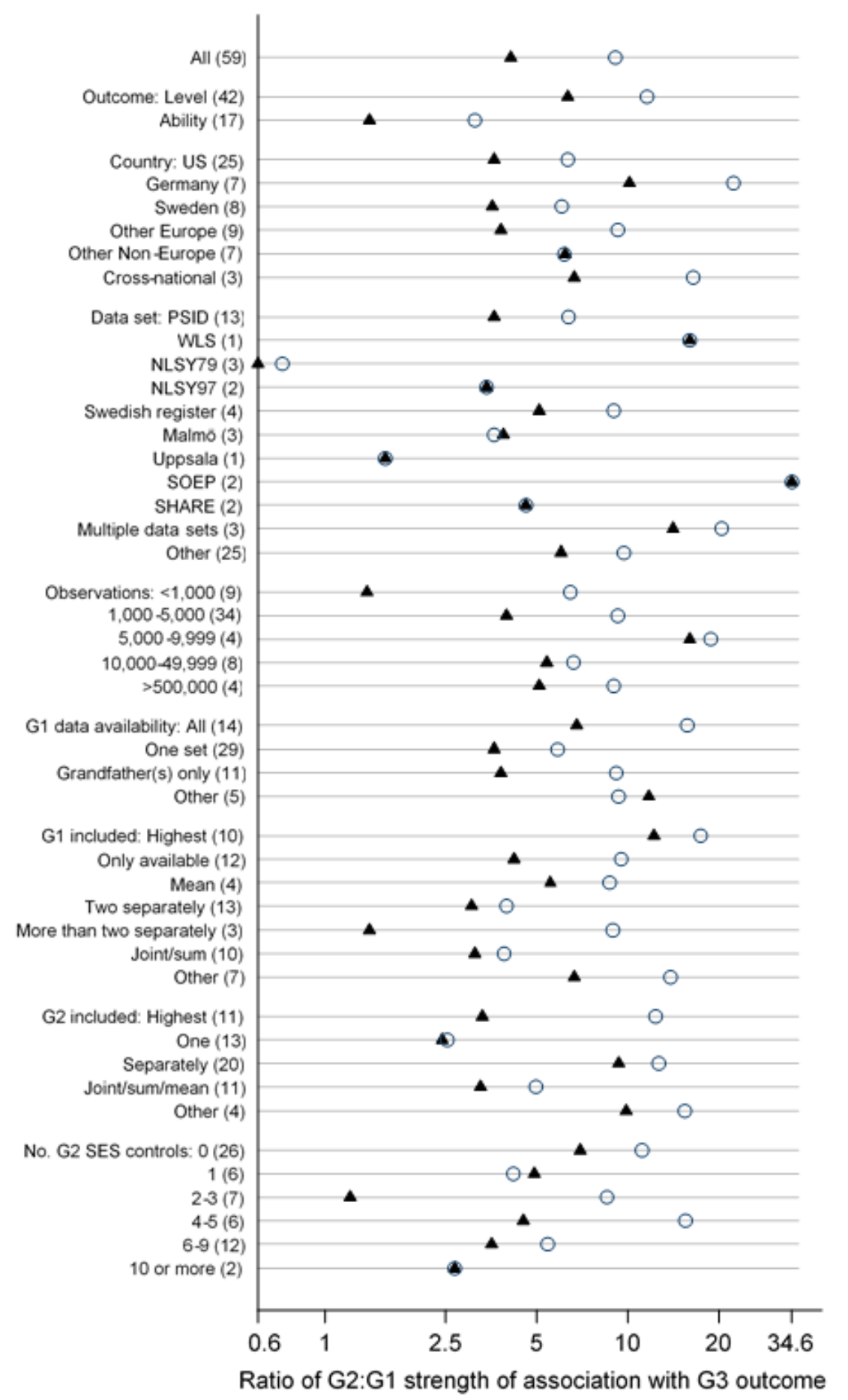

\section{- Mean ^ Median}

Figure 3: Ratio of G2:G1 (parent to grandparent) strength of association with G3 (grandchild) outcome: mean and median by analysis characteristics. Notes: The number of observations in each category is included in parentheses. A larger number corresponds to a stronger G2-G3 association relative to the G1-G3 association. 


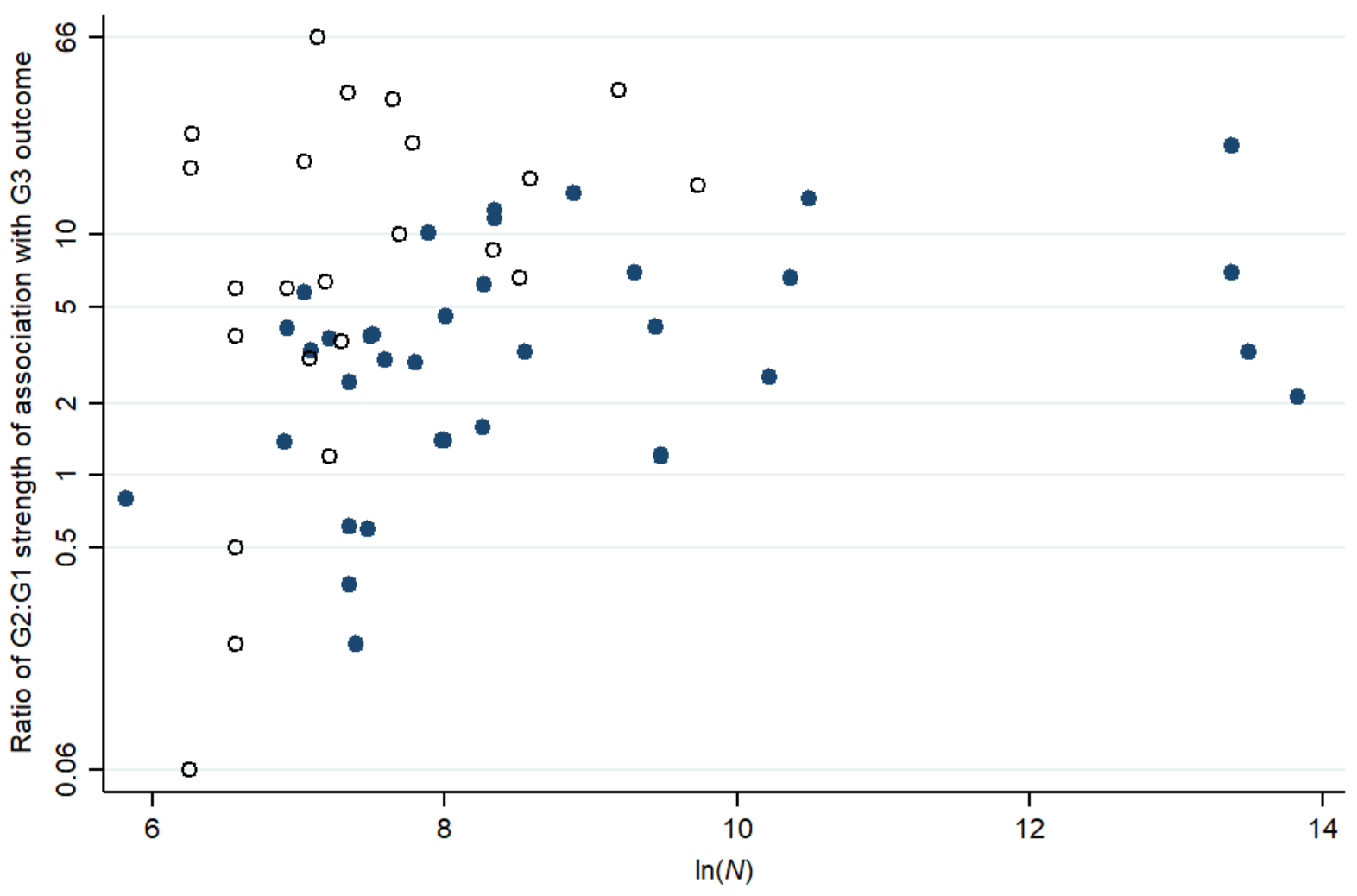

- Significant O Nonsignificant

Figure 4: Ratio of G2:G1 (parent to grandparent) strength of association with G3 (grandchild) outcome by $\ln (N)$ and whether estimates are significant. $N=59$. Note: Each point corresponds to an analysis. A larger number on the $y$ axis corresponds to a stronger G2-G3 association relative to the G1-G3 association.

trend of smaller ratios observed for ability outcomes may be a product of samples being younger and thus more likely experience face-to-face interaction with their grandparents, as discussed below.

Also notable from these results is dependence on how G1 and G2 are modelled: including two grandparents separately shows a tendency towards a lower ratio, supporting Sheppard and Monden's (2017) finding that the effects of grandparents, or at least grandfathers, are additive. Similarly, estimates in which only one parent is included (mean ratio 2.5) appear to give more weight to grandparents than if both parents are modelled separately (mean ratio 12.7), again suggesting additive contributions, though they may be picked up by modelling the most-educated parent (mean ratio 12.3).

As noted, the ratio does not vary systematically with sample size (Figure 4). Interestingly, the four analyses using Swedish register data, with $N>500,000$, give estimates ranging from 2.11 to 23.50 . The variability in estimates of the ratio does 


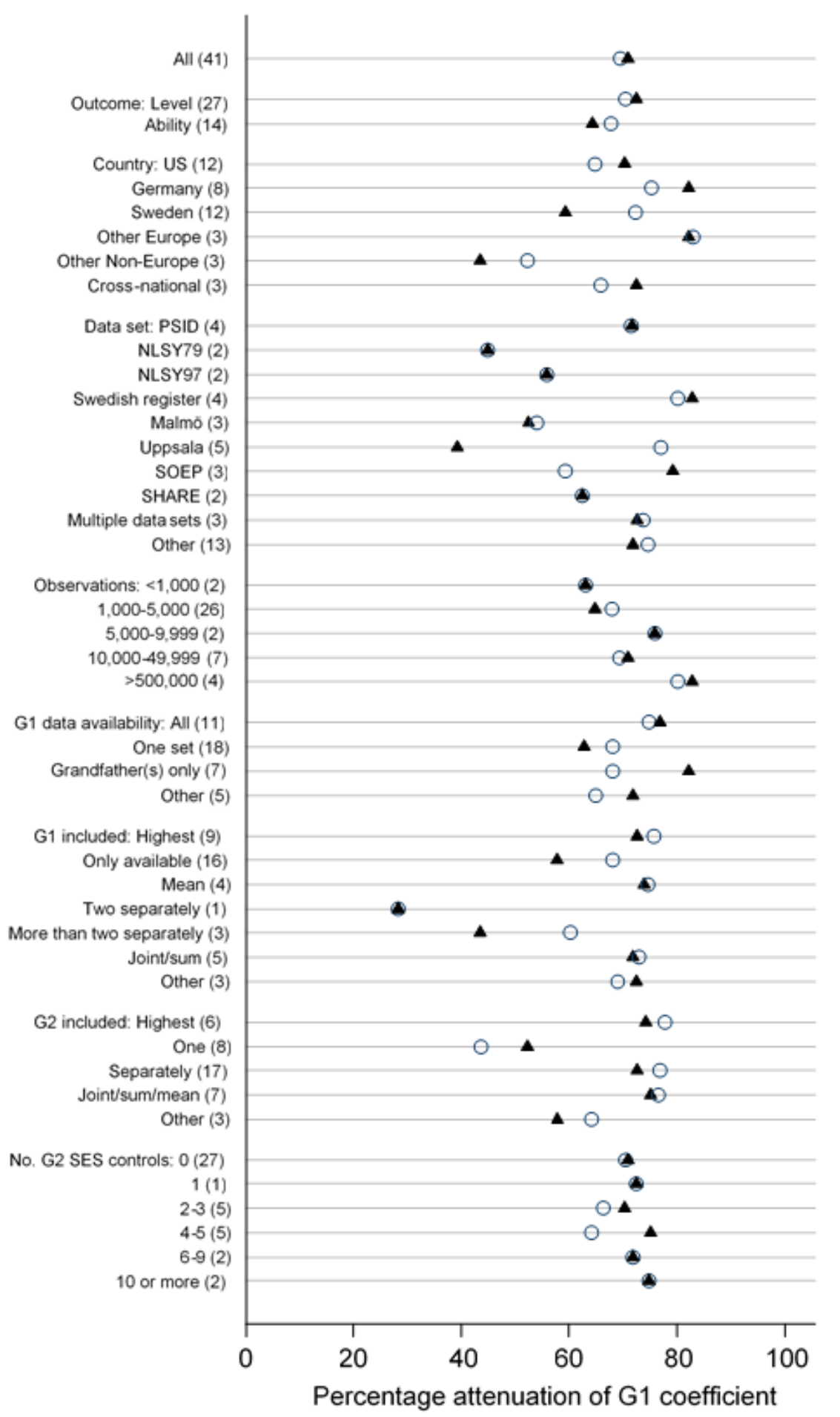

Figure 5: Attenuation in G1 coefficients from bivariate to full model: mean and median by analysis characteristics. Note: The number of observations in each category is included in parentheses. 


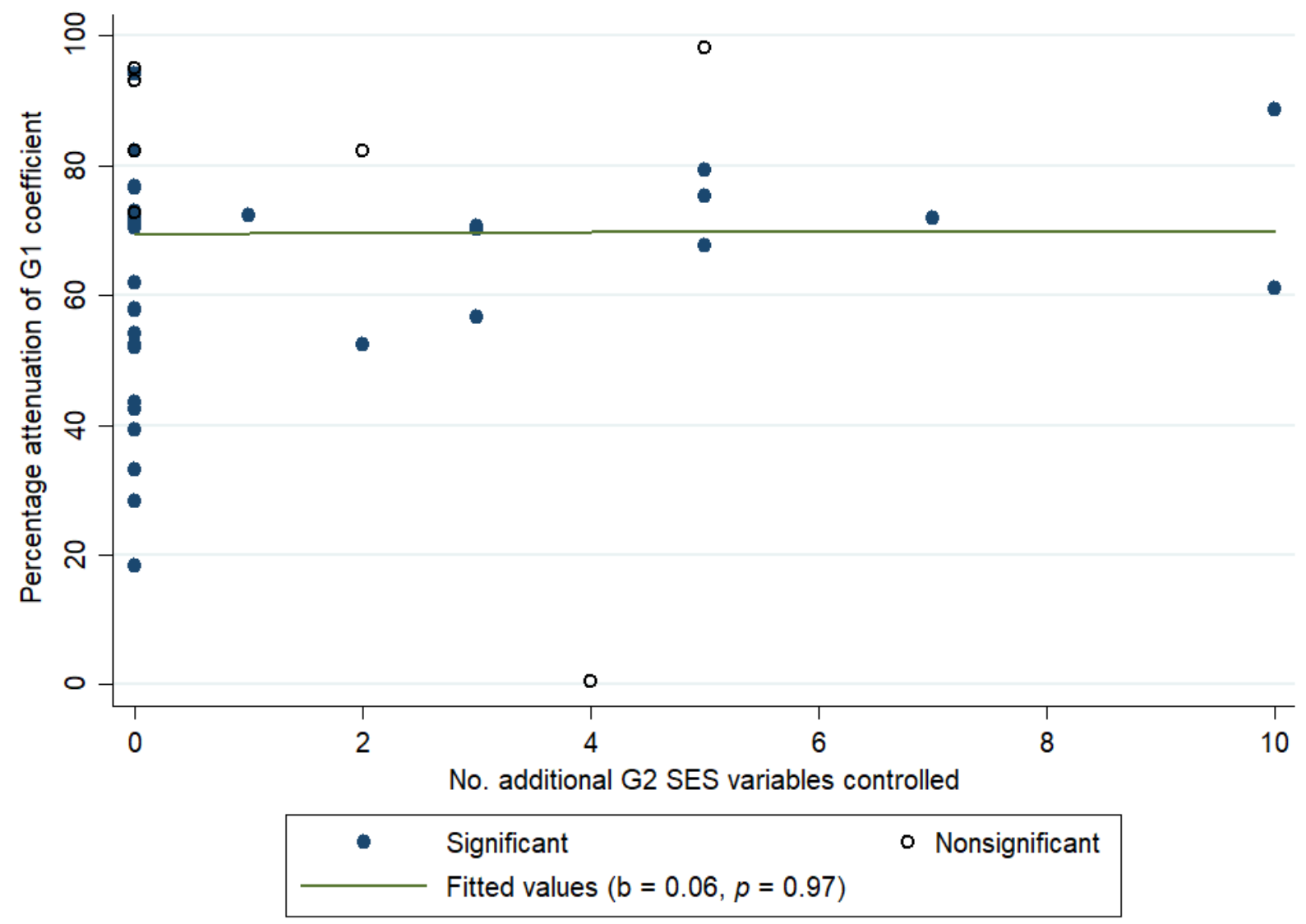

Figure 6: Percentage attenuation in G1 coefficient(s) from bivariate to full model by number of parental SES controls (in addition to parental equivalent of G1 resource) and whether estimates are significant. Note: each point corresponds to an analysis. This figure does not show three analyses in which G1 coefficient attenuation is greater than 100 percent. $N=41$.

appear to decline in the better-powered analyses. Above $N=3,000$ ( 8 on the $x$ axis of Figure 4), ratios tend to fall within the range 2 to 10.

\section{Attenuation with Inclusion of Controls}

Estimates of the G1 coefficient(s) consistently attenuate by around 70 percent from the bivariate model when covariates including the G2 measures are introduced (Figure 5). Figure 6 suggests that this bears little relation to the number of G2 SES controls included. Although data points are sparse, this pattern is consistent with the hypothesis that omitted aspects of parental SES may not be important mediators of G1 influence because the studies that do control for a larger number of such variables do not show clearly greater levels of attenuation in the G1 coefficient.

This attenuation parameter appears to vary only according to how parents are modelled: including just one parent, unless they are the most educated, may omit important information on G2 SES. A partial explanation of this pattern may be that 
including only one parent fails to capture a potentially important pathway through which grandparents influence their grandchildren: their role in the assortative mating of their (G2) child and hence in the choice of their grandchild's other parent and set of grandparents (see below).

\section{Potential Mechanisms Underlying a Direct Effect of Grandparents}

Contact-based. Many of the mechanisms through which a direct grandparent effect is hypothesized to occur depend upon interaction between grandparent and grandchild. Through face-to-face interaction, the established mechanisms through which parents influence children-modeling behaviors, teaching values and norms, reading with the child, and so on-are analogously open to grandparents. This implies that in the presence of true grandparent effects, G1-G3 associations will be stronger in cases in which grandparents are able or likely to have been in contact with the grandchild and weaker where this does not hold-for instance, where the grandparent(s) died early in the grandchild's life or even before their birth. A finding of stronger grandparental effects where the grandparent is closer to the family could, however, also result from lower measurement error in parental reporting of grandparent resources in cases in which the grandparent is present, or from unobserved characteristics of grandparents correlating with their availability, so this would not unambiguously confirm the presence of grandparent effects.

Several studies test such grandparental availability interaction terms. Table 1 summarizes these findings. In general, coefficients for grandparental resources do not appear to differ depending on the likelihood of contact between grandparent and grandchild, though there are exceptions, most notably Zeng and Xie's (2014) finding that the education of coresident grandparents in rural China is almost as strongly associated with the likelihood of school dropout as mother's and father's education. However, this finding from rural China is a special case and not generalizable to Europe or the United States, where coresidence with grandparents is uncommon. It should be noted that the measures used in these analyses are mostly, as a function of the available data, crude proxies for grandparent-grandchild contact.

Results are similar for studies that test for a main, rather than moderating, effect of grandparental availability. Wightman and Danziger (2014:67) find that the child having at least one living grandparent shows no effect, and Ferguson and Ready report similar null results for variables indicating the number of living grandparents and whether they lived in proximity (2011:219). Celhay and Gallegos's main effect for whether any grandparent is still alive is also non-significant (2015:443).

Non-contact-based. Direct influence of grandparents on grandchildren is also possible through means that do not require contact. Indeed, the most intuitive channel for grandparent effects is direct financial transfers. Hällsten and Pfeffer (2017:331-34) provide a discussion of further mechanisms through which family wealth may influence educational outcomes. Dead grandparents may also have social capital in the form of contacts that aid their grandchildren, or they may serve as reference points for their descendants' decision-making in the status attainment 
Table 1: Studies testing interactions with grandparental likelihood of contact.

\begin{tabular}{|c|c|c|}
\hline Study & $\begin{array}{l}\text { Grandparent resources interacted } \\
\text { with. . }\end{array}$ & Interaction significant? \\
\hline $\begin{array}{l}\text { Neidhöfer and Stockhausen } \\
\text { forthcoming }\end{array}$ & $\begin{array}{l}\text { GP dead when grandchild was } \\
\text { age } 1\end{array}$ & $\begin{array}{l}\text { Yes, but only for maternal grand- } \\
\text { fathers, and only in German data }\end{array}$ \\
\hline Sheppard and Monden 2017 & Lifespan overlap & No \\
\hline Braun and Stuhler 2017 & $\begin{array}{l}\text { Grandfather dead when grand- } \\
\text { child born (with WWII deaths as } \\
\text { a source of exogenous variation) }\end{array}$ & No \\
\hline Daw and Gaddis 2016 & $\begin{array}{l}\text { GP still alive when grandchild } \\
\text { was age } 6\end{array}$ & No \\
\hline Bol and Kalmijn 2016 & Tie strength, residential proximity & No \\
\hline Kroeger and Thompson 2016 & $\begin{array}{l}\text { Mother lived with one of the } \\
\text { child's GPs for three months or } \\
\text { more after child born }\end{array}$ & No \\
\hline Zeng and Xie 2014 & $\begin{array}{l}\text { Number and education of cores- } \\
\text { ident, noncoresident, and de- } \\
\text { ceased GPs }\end{array}$ & $\begin{array}{l}\text { Yes, effect of education far } \\
\text { stronger for coresident than } \\
\text { noncoresident or deceased GPs }\end{array}$ \\
\hline Ferguson and Ready 2011 & $\begin{array}{l}\text { "[C]o-resident versus caregiver } \\
\text { status" }\end{array}$ & No \\
\hline Loury 2010 & $\begin{array}{l}\text { GP dead when grandchild born } \\
\text { or geographically remote during } \\
\text { childhood }\end{array}$ & Yes, but only for grandmothers \\
\hline
\end{tabular}

Notes: GP = grandparent.

process (Hertel and Groh-Samberg 2014). It is also possible for grandparents to pass on advantageous genetic material that is not expressed in the parental generation.

Although Braun and Stuhler claim the lack of an interaction between grandfather schooling and early death as evidence for indirect mechanisms of status transmission across three generations (2017:30), direct evidence on these mechanisms is extremely sparse.

\section{Inclusion of Both Parents, and Assortative Mating as an Indirect Mechanism for Grandparent Effects}

We have seen that grandparent effects are relatively weak and attenuate to a greater extent from bivariate estimates when both parents rather than just one are included in the model.

A possible explanation for a (stronger) grandparent effect in cases in which the status of only one parent is controlled is a correlation between the characteristics of G1 and the other, omitted parent. Though this would represent a technically 
spurious portion of the G1-G3 association, it may reflect an important indirect mechanism through which grandparents can influence the development of their grandchildren. Such a correlation may arise if grandparents exert an influence on their child's choice of spouse - the other parent to their grandchild. Conversely, the same will occur if G2 individuals' choice of partner is informed by the status of the parents of a potential partner, whether directly or simply through observation of characteristics of the potential partner, without reference to their parents.

Few analyses present separate results including one parent and then both. These are presented in Table 2. Only a subset of these bear upon this assortative mating hypothesis (i.e., results for G1 and their descendant G2, then adding the nondescendent G2). In many cases, the second parents added are a mixture of individuals descendant and nondescendant from the G1 individual. The three analyses showing the G1 coefficient both before and after the son- or daughter-in-law is added each show an attenuation close to 50 percent, suggesting a substantial correlation between G1 and son- or daughter-in-law characteristics and hence the importance of assortative mating as an indirect pathway for G1 influence-though the process of partner choice may be entirely independent of G1's actions. The broader set of results suggest that including the mother in addition to the father accounts for a large portion (mean $=57.2$ percent) of any G1-G3 association that is evident when the status of only the father is controlled.

\section{The Distribution of Grandparent Effects}

Grandparent effects may be stronger among certain subgroups. Indeed, the loglinear models of Pfeffer (2014, education, United States), Chan and Boliver (2013, social class, United Kingdom), and Hertel and Groh-Samberg (2014, social class, Germany and the United States) all suggest stronger multigenerational persistence at the ends of the status distribution. So too do the transition matrices shown by Lindahl et al. (2015) for both earnings and education and the mobility approach taken by Ziefle (2016), though in the latter case only for West and not East Germany.

Authors taking a regression approach have tended to frame the nonlinearity issue as one of compensation (stronger grandparent effects where parental resources are low) versus augmentation (stronger grandparent effects where parental resources are high). It is noteworthy that this implicitly rejects the possibility of stronger effects at both ends of the distribution of parental resources than closer to the mean. This framing perhaps results from the difficulty of specifying terms in a regression framework to accommodate testing this possibility. Rather, where nonlinearities are tested, a simple interaction between parent and grandparent resources is included. These tests are reported in Table 3. Results are mixed, but more often than not, the hypothesis of compensation is supported and with interactions of greater magnitude than in those cases in which augmentation is supported. This is in line with Bengtson's (2001) argument that grandparents represent an important source of support that may often not be recognized and harnessed except in conditions of difficulty. On the grandparent (supply) side, this accords with "the two main cultural norms of grandparenting [identified in the UK]. . .'being there' and 'not interfering"' (Mason, May, and Clarke 2007:687). 
Table 2: Analyses presenting separate results including one parent and then both.

\begin{tabular}{|c|c|c|c|c|}
\hline Analysis & $\begin{array}{l}\text { Grandparents } \\
\text { included }\end{array}$ & $\begin{array}{l}\text { Second parent } \\
\text { added }\end{array}$ & $\begin{array}{l}\text { \% attenuation of } \\
\text { grandparent } \\
\text { coefficient }\end{array}$ & $\begin{array}{c}\text { Grandparent effect } \\
\text { becomes nonsignificant? }\end{array}$ \\
\hline $\begin{array}{l}\text { Sheppard and } \\
\text { Monden } 2017\end{array}$ & $\begin{array}{c}\text { No. of } \\
\text { educated GFs }\end{array}$ & Mother & 40.0 & No \\
\hline $\begin{array}{l}\text { Braun and Stuhler } \\
2017 \text { (LVS-1) }\end{array}$ & M-GF or P-GF & Mother & 115.6 & Yes \\
\hline $\begin{array}{l}\text { Braun and Stuhler } \\
2017 \text { (LVS-2) }\end{array}$ & M-GF or P-GF & Mother & 25.5 & No \\
\hline $\begin{array}{l}\text { Braun and Stuhler } \\
2017 \text { (BASE) }\end{array}$ & M-GF or P-GF & Mother & 74.7 & $\begin{array}{l}\text { Already nonsignificant } \\
\text { with only one parent (and } \\
\text { stays nonsignificant) }\end{array}$ \\
\hline $\begin{array}{l}\text { Braun and Stuhler } \\
2017 \text { (NEPS-1) }\end{array}$ & M-GF or P-GF & Mother & 41.1 & Yes \\
\hline $\begin{array}{l}\text { Braun and Stuhler } \\
2017 \text { (NEPS-2) }\end{array}$ & M-GF or P-GF & Mother & 60.3 & No \\
\hline $\begin{array}{l}\text { Daw and Gaddis } \\
2016 \text { (years of } \\
\text { education) }\end{array}$ & Highest & $\begin{array}{l}\text { Nondescendant } \\
\text { of G1 }\end{array}$ & 52.4 & Yes \\
\hline $\begin{array}{l}\text { Daw and Gaddis } \\
2016 \text { (whether } \\
\text { attained bachelor's } \\
\text { degree) }\end{array}$ & Highest & $\begin{array}{c}\text { Nondescendant } \\
\text { of G1 }\end{array}$ & 62.2 & Yes \\
\hline Stuhler 2014 & P-GF & $\begin{array}{c}\text { Mother } \\
\text { (nondescendant } \\
\text { of G1) }\end{array}$ & 43.2 & No \\
\hline
\end{tabular}

Notes: $\mathrm{P}-\mathrm{GF}=$ paternal grandfather; $\mathrm{M}-\mathrm{GF}$ = maternal grandfather.

If, as the loglinear evidence mentioned above suggests, grandparent effects are especially strong at both ends of the parental status distribution, the interaction terms tested in this framework may be biased towards zero. Just as there are good reasons to expect grandparents to step up in times of need, there are mechanisms for the direct grandparental transmission of advantage that are especially concentrated at the top of the status distribution, such as college legacy admissions and trust funds.

Heterogeneity is also possible according to family structure in the parental generation. Song (2016) focuses on this question, noting that stronger effects are plausible both in single-parent families (analogous to the compensation hypothesis, the necessity of their assistance may "activate" the grandparent effect) and in two-parent families, in which more grandparents are likely to be in contact with the grandchild. Song finds a significant G1-G3 association only among married, two-parent families and not for families in which a child's parents are divorced or unmarried. 
Table 3: Studies testing interactions of grandparent and parent resources.

\begin{tabular}{|c|c|c|}
\hline Study & $\begin{array}{l}\text { Augmentation, compensation, } \\
\text { or linearity? }\end{array}$ & $\mathrm{b} 1(\mathrm{GP})+\mathrm{b} 2(\mathrm{P})+\mathrm{b} 3(\mathrm{GP} \times \mathrm{P})$ \\
\hline $\begin{array}{l}\text { Sheppard and Monden } \\
2017\end{array}$ & Linearity & \\
\hline Braun and Stuhler 2017 & Compensation & $\begin{array}{l}\text { GP coefficient: } 0.334(\text { father's ed. }=\text { low }) \text { vs } \\
0.017 \text { (father's ed. } \neq \text { low); } 0.453(\mathrm{G} 2 \\
\text { respondent income }=\text { low) vs. } 0.071(\mathrm{G} 2 \\
\text { respondent income's } \neq \text { low })\end{array}$ \\
\hline Deindl and Tieben 2016 & Compensation & $\begin{array}{l}0.49+1.20-0.27 \text { (high ed.); } 0.65+0.64- \\
\mathbf{0 . 5 5} \text { (financial resources) }\end{array}$ \\
\hline Daw and Gaddis 2016 & $\begin{array}{l}\text { Augmentation (but not robust } \\
\text { to inclusion of cousin } \\
\text { fixed effects) }\end{array}$ & e.g., $-0.158+0.243+\mathbf{0 . 0 1 5 8}$ (ed.) \\
\hline Chiang and Park 2015 & Augmentation & e.g., $-0.174+0.100+\mathbf{0 . 0 1 2}$ (ed.) \\
\hline Wolbers and Ultee 2013 & Compensation & $0.04+0.20-0.06$ (ed.) \\
\hline $\begin{array}{l}\text { Havari and Savegnago } \\
2012\end{array}$ & Compensation & $\begin{array}{l}\text { e.g., } 0.516+0.906-0.357 \text { (ed., proxied by } \\
\text { number of books for GPs) }\end{array}$ \\
\hline Jæger 2012 & Compensation & e.g., $0.140+0.257-0.010$ (ed.) \\
\hline
\end{tabular}

Notes: ed. = education; GP = grandparent; $\mathrm{P}=$ parent.

\section{Are Certain Grandparents More Important?}

Two types of evidence on this question are reported in Supplementary Table 3 (online supplement): firstly, cases in which terms for grandparents are included separately in a model, such as grandfather's and grandmother's education (single sample); and secondly, cases in which the sample is split according to which grandparent(s) are available and analogous models are fitted to, for instance, the halves of the sample with information on maternal and paternal grandparents. Where samples are split like this, separate models are indicated with a), b), c), et cetera.

There is no clear pattern to the results. It occurs slightly more often that a grandfather term is significant and a grandmother term is not than vice versa. Even a striking pattern could only be suggestive because the difference between a significant and a nonsignificant term may not itself be significant.

Sheppard and Monden (2017) note, having fitted 14 different specifications of all four grandparents to data from 15 countries separately, that "the only consistent finding across models is that, where there is an association, it tends to be for highly educated grandfathers and there is little evidence for an influence of grandmothers in any country" (p. 14).

\section{Robustness of Findings to Alternative Specifications}

We here examine stability and change in results according to within-sample variation in the operationalization of grandparent resources (Table 4). Evidence for grandparent effects will be more compelling if it is not dependent upon a priori 
Table 4: Robustness of findings to different operationalizations of grandparental resources.

\begin{tabular}{|c|c|c|}
\hline Study & $\begin{array}{l}\text { Different approaches to including } \\
\text { grandparents }\end{array}$ & Different results from different models? \\
\hline $\begin{array}{l}\text { Neidhöfer and } \\
\text { Stockhausen } \\
\text { forthcoming }\end{array}$ & $\begin{array}{l}\text { - Using unstandardized years of } \\
\text { education and most educated (of 4) GPs } \\
\text { - Using unstandardised years of } \\
\text { education and each GP separately } \\
\text { (stratified by sex of grandchild) } \\
\text { - Using years of education z-scores and } \\
\text { most educated (of 4) GPs } \\
\text { - Using years of education z-scores and } \\
\text { each GP separately (stratified by sex of } \\
\text { grandchild) }\end{array}$ & $\begin{array}{l}\text { Using unstandardized years of } \\
\text { education: yes } \\
\text { Using z-scores: no }\end{array}$ \\
\hline $\begin{array}{l}\text { Sheppard and } \\
\text { Monden } 2017\end{array}$ & $\begin{array}{l}\text { Evaluate model fit and GP effects using } \\
14 \text { different operationalizations of GPs } \\
\text { (with data on all 4); do this for full } \\
\text { sample and } 15 \text { countries separately }\end{array}$ & $\begin{array}{l}\text { Model fit: no } \\
\text { Best-fitting model and GP effects: yes, } \\
\text { but "no clear patterns" (p. 14) }\end{array}$ \\
\hline Hancock et al. 2016 & $\begin{array}{l}\text { - All } 4 \text { GPs' (and Ps') levels of ed. } \\
\text { separately } \\
\text { - For each set of GPs (and Ps), whether } \\
\text { GF, GM, or both have tertiary ed. }\end{array}$ & No \\
\hline Ferrie et al. 2016 & $\begin{array}{l}\text { - Most educated observed GP (and P) } \\
\text { - Mean education of GPs (and Ps) } \\
\text { - Most educated observed GP (and P), } \\
\text { with terms for other GPs (and Ps) also } \\
\text { included } \\
\text { - Most educated GP (and P), with mean } \\
\text { education of GPs (and Ps) also included }\end{array}$ & No \\
\hline Song 2016 & $\begin{array}{l}\text { - Most educated GP (usually either } \\
\text { maternal or paternal GPs observed) } \\
\text { - Average education of GPs }\end{array}$ & No \\
\hline Stuhler 2014 & $\begin{array}{l}\text { - Paternal GF only } \\
\text { - All } 4 \text { GPs separately (halves sample } \\
\text { size) }\end{array}$ & Yes \\
\hline $\begin{array}{l}\text { Wightman and } \\
\text { Danziger } 2014\end{array}$ & $\begin{array}{l}\text { - One set of GPs } \\
\text { - Both sets of GPs }\end{array}$ & No \\
\hline Zeng and Xie 2014 & $\begin{array}{l}\text { - Sum of percentile scores } \\
\text { - Mean percentile score } \\
\text { - Maximum percentile score } \\
\text { - Sum of years of schooling }\end{array}$ & No \\
\hline Grant 2005 & $\begin{array}{l}\text { - M-GPs' wealth } \\
\text { - P-GPs' wealth } \\
\text { and } \\
\text { - M-GPs' income } \\
\text { - P-GPs' income }\end{array}$ & No \\
\hline
\end{tabular}

Notes: Supplementary Table 4 (online supplement) gives a more detailed version of this table, elaborating on how results change between models. GP = grandparent; $\mathrm{P}$ = parent; ed. = education; $\mathrm{GF}=$ grandfather; $\mathrm{GM}$ = grandmother; $\mathrm{M}-\mathrm{GP}=$ maternal grandparent; P-GP = paternal grandparent. 
minor changes in model specification. This is indeed usually the case, insofar as such checks are reported. It may of course be that authors are reluctant to report instability of findings to specification changes, should this occur.

\section{Limitations to the Accurate Estimation of Grandparent Effects}

Measurement error, collinearity, and omitted variables each have implications for the interpretation of grandparent effects. First, in certain circumstances, random measurement error is likely to be greater for grandparental characteristics than for parental characteristics, which would act to suppress any true G1-G3 association. This applies when, as is usually the case, both parental and grandparental characteristics are reported by G2-that is, by grandparents' adult offspring and in some cases by their sons- or daughters-in-law. Respondents are likely to be able to make a more accurate report of their own and their partner's socioeconomic resources than of their own parents' and in-laws'.

In addition, information is usually not available on all four grandparents, which may further introduce random measurement error. This depends upon the missingness of grandparent measures being random, which holds in the many cases for which either maternal or paternal grandparents are observed, depending on the gender of the G2 survey respondent.

Second, conversely, where information on all four grandparents is used, including terms for each of them may introduce collinearity if the resources of an individual's grandparents are highly correlated, as may be the case under a high degree of assortative mating. This would decrease efficiency and make a true grandparent effect less likely to be found.

Third, a potential source of bias lies in the measurement of $\mathrm{G} 2$ resources, both through classical measurement error and through omitted variables. In the standard model regressing G3 education on G2 and G1 education, measurement error in the former will attenuate its association with the outcome and upwardly bias the G1 coefficient. As mentioned, this issue is more likely to take the opposite form, with random measurement error higher among G1 than G2. However, Ferrie et al. (2016) show that their finding of a significant grandparent effect is consistent with a Markov process in which the level of measurement error in education is the level that they in fact observe from their multiple data sources: "The grandparent effect we observe. . .either does not exist or is too small for us to distinguish from measurement error" (2016:19).

Of even greater a priori concern is the omission of G2 characteristics different from the G1 characteristic of interest but which also mediate the transmission of advantage between generations. For example, if grandparental education exerts indirect effects on grandchild education not only through parental education but also through parental income, failing to control for parental income will upwardly bias the independent G1-G3 association and give the appearance of a direct grandparent effect. The results above give some assurance that apparent grandparent effects do not necessarily reflect unobserved pathways involving some attribute of the intervening generation. 
Although this omitted-variables argument is most often put in terms of unmeasured parental characteristics, it extends to the characteristics of other family within the parents' generation. Aunts, uncles, and others embody a pathway for the transmission of advantage from grandparent to grandchild, but their resources are rarely measured in the data sets informing this literature. Loury (2006) reports that aunts, uncles, and grandparents each independently affect grandchildren's educational outcomes, though Jæger (2012) finds an effect only for aunts' education among extended family in G2 and no grandparent effects. The most striking evidence on this issue is afforded by the unique comprehensiveness of Swedish register data: Adermon, Lindahl, and Palme (2016) show that the coefficient for grandparents' human capital on grandchildren's years of schooling falls from 0.044 to 0.012 when a greater range of individuals from G2 are taken into account (aunts and uncles, their spouses, the siblings of their spouses, parents' cousins, and their spouses). The attenuation is similar whether schooling, schooling and income, or schooling, income, and occupation are used to measure relatives' human capital.

\section{Alternative Analytical Approaches}

Several studies apply analytical approaches more complex than standard regressions and are not included in our quantitative review. We discuss these contributions here. These approaches are instrumental variable (IV) models, marginal structural models (MSMs), and the use of cousin correlations in outcomes.

IV models offer a promising approach, but the small number of such analyses in this area likely reflects the scarcity of appropriate instruments. Behrman and Taubman (1985), Lindahl et al. (2014), and Sauder (2006) each employ instrumental variables in models regressing G3 education on G1 and G2 characteristics. The former two use the education of fathers' twins and the education of G2's grandparents, respectively, as instruments for G2 education. The aim in these cases is not, therefore, to identify a causal effect of G1 but rather of G2. In contrast to their ordinary least squares (OLS) results, Behrman and Taubman found in their IV models a positive and significant association for grandfather's (but not grandmother's) education. However, little information is given about the strength and appropriateness of the instrument, and as Lindahl et al. (2014:88) observe, the exclusion criterion that the education of one twin does not directly influence the education of the other twin's children is questionable. Lindahl et al. report positive coefficients of similar size in their OLS and IV regressions, but the larger standard errors in the IV models mean that the grandparent effect is significant only in the OLS results. In each of these two analyses instrumenting G2 education, the G2:G1 ratio is around 4. These analyses offer tentative support for a grandparent effect, but both depend on strong assumptions and come from relatively small samples that are not nationally representative. Moreover, they instrument G2 rather than G1 education.

Sauder's (2006) unpublished study appears to represent the only attempt to directly instrument G1 characteristics. This analysis does so using both a schooling reform (the 1947 increase in the UK minimum school leaving age) and grandmothers' birth order. Sauder's instruments are also imperfect. The increase in education associated with the schooling reform (instituted simultaneously nationwide) is con- 
founded by age, and the use of birth order has been criticized on the grounds that it can have effects other than through education (Black, Devereux, and Salvanes 2005; Lindahl et al. 2014). Another caveat is that the G2 spousal correlation in education is unusually low at 0.19 . Sauder cautions that his analysis "could not reach sufficient precision to identify causal effects" (2006:49), but finding no evidence in the IV models for a grandparent effect (or a positive effect of parental education) despite positive OLS results, he concludes that "all evidence presented seems to indicate that OLS effects are overestimating the true effects of education" (ibid.).

Three studies report results from marginal structural models as well as more conventional regression models. This method aims to account for time-varying confounding by weighting such that the conditional distributions of the variables of interest are independent of any time-varying confounders (Robins, Hernán, and Brumback 2000). In two cases the MSMs aim to capture the total-direct and indirect-effect of grandparents and are thus less relevant here (Sharkey and Elwert 2011; Hällsten and Pfeffer 2017). Song (2016), however, applies the method to the question of direct grandparent effects. Although she does not discuss the differences in the results, Song's MSM finds a significant grandparent effect (with a G2:G1 strength of association ratio of 5.4), whereas her conventional model does not (G2:G1 ratio of 17.1). This suggests that time-varying covariates may suppress conventional estimates of grandparent effects.

Finally, Jæger (2012) and Hällsten (2014) examine correlations in educational outcomes between cousins, who by definition share one set of grandparents. Cousin correlations, however, capture all influences shared by cousins, which potentially extend well beyond the direct effects of grandparents. In Jæger's analysis, the intraclass correlation coefficient for cousins becomes nonsignificant once G2 socioeconomic characteristics are controlled, suggesting an absence of direct grandparental influence. Hällsten finds cousin correlations of more than 0.15 for educational outcomes, which are reduced by around one-third to one-half after accounting for G2. For those who share extremely wealthy grandparents, however, these correlations are far larger, more than 0.20 even after adjustment for G2. In line with Hällsten and Pfeffer's (2017) test for a direct effect, this suggests an important role for grandparental wealth, especially at the top of the distribution. As noted, however, influences shared by cousins may include not just grandparents but also, for instance, "economic conditions, manners and cultural behaviors, and network connections" (Hällsten 2014:23).

\section{Conclusions and Future Directions}

At first sight, the extant evidence gives a remarkably incoherent picture as to whether grandparental resources are associated with the educational outcomes of their grandchildren independently of the characteristics of the parental generation: 58 percent of the 69 analyses that model this relationship report a significant association. Other than sample size, no study characteristics clearly distinguish the positive findings from the null. However, given the clear correlation between sample size and finding a significant association, the more interesting question is the following: how substantively large is the grandparent effect? Across analyses that use a highly 
heterogeneous set of measures, we examine this by extracting the ratio of parent and grandparent independent associations with the grandchild outcome. The median for this parameter is 4.1, implying that grandparents matter around a quarter as much as parents for education. As sample size increases, variability in this parameter declines, and most estimates imply that the independent G1-G3 association is around a half to a tenth the size of the G2-G3 association. Taken together with the finding that on average, 30 percent of the bivariate G1-G3 association remains after the inclusion of G2 controls, it is clear that grandparental characteristics often contribute information beyond that captured by parental characteristics and should be included in measurements of social origin.

We draw a number of further conclusions. First, with the notable exception of Zeng and Xie's (2014) finding in the context of rural China, there have been consistent null results for the hypothesis that G1-G3 associations should be stronger where there is (more) G1-G3 contact. This casts doubt on a causal interpretation of the grandparent effect. Second, based on the few studies that report the relevant information, adding the second parent substantially attenuates the grandparent effect, suggesting that assortative mating is an important indirect mechanism. Third, although there are good reasons to expect stronger effects at both ends of the distribution of G2 resources, the compensation hypothesis is well-supported: grandparent effects are stronger where G2 resources are low. Fourth, it is not clear that any particular grandparents are especially important in general, and this may vary with factors such as the outcome (Modin, Erikson, and Vågerö 2013) and sex of the grandchild (Celhay and Gallegos 2015). Fifth, the omitted-variables critique of grandparent effects is an important caveat, but its implication that a grandparent effect should be less likely to be found with more controls for parental characteristics is not clearly borne out here, albeit in an imperfect test, and one that attends only to between-analysis variation in the number of additional G2 SES controls. It should be borne in mind that, as in any model, using a greater number of controls does not necessarily reduce the association of interest. Moreover, if (G2) controls are uncorrelated with the (G1) predictor and/or (G3) outcome, efficiency of estimates may be reduced, which has the potential to affect whether a G1-G3 association appears statistically significant.

It is surprising that variation in G1-G3 associations by measures of the likelihood of contact is not more evident. If grandparents directly affect their grandchildren, the association is expected to be stronger if the grandparents, for instance, live nearby and overlap substantially in lifespan. This approach is limited, however, because the relationship between modes of grandparental influence and measures of availability is not necessarily clear. For instance, geographically distant grandparents may provide fewer economic resources because they have less contact and so take less of an interest in their descendant, or they may provide more to compensate for the relative lack of contact. Similarly, living grandparents may provide more economic resources as they take an active interest in the child's development, or deceased grandparents may do so because they provide an inheritance and have zero consumption themselves. Measures of grandparental availability would usefully be combined with other information on grandparental characteristics to enable 
researchers to determine whether particular mechanisms rely upon some aspect of contact or availability.

No research has yet explored the dynamic aspects of grandparent effects: variation in availability-especially conceived of as health and well-being-exists within individual grandparents as well as between them. This raises questions of whether and at what point aging grandparents begin to compete with the youngest generation for resources rather than providing them, and so whether their net effect varies according to the time at which it is measured and if it depends upon health and longevity. Competing hypotheses are plausible: high-SES grandparents have more resources to pass on, yet may live longer and in doing so demand resources from the parental and even child generation. This may have implications for the educational success of grandchildren.

Further work is needed to disentangle the nature of grandparent effects. To advance our understanding it will need to attend to measurement error and omitted variables with regard to the parental generation-including aunts and uncles if possible (Prix and Pfeffer 2017). Given the mixed set of results arising from the few IV and MSM analyses conducted so far, it would be useful for researchers to take these approaches further and to attempt to explicitly account for differences from conventional regression estimates that these methods produce. Future research will also need to pay close attention to sources of heterogeneity and in particular the conditions under which (and ways in which) grandparents are drawn out of the ambivalence of their position with respect to their grandchildren's development (Mason et al. 2007) and mobilized as cultivators of their human capital. This will require attention to the institutions and actors that structure G1-G3 contact, including paternity/maternity leave, childcare regimes, and parents themselves. With variation across cultures in the role of grandparents, mechanisms may be context specific. It is the task of future research to identify these.

Though we are able to draw a number of important conclusions, there remains a great deal of variability across analyses. This review is based on 69 analyses from 40 articles. Set against the number of studies on many other substantive questions in stratification and social mobility, this is a relatively small body of evidence. More studies using more data sources and covering more time periods and societies may give us clearer patterns than we can see currently. It is crucial, therefore, that all well-designed studies are published, whether they find significant associations or not. We have no way of knowing the extent of publication bias in this field; however, it is encouraging that we find a relatively high proportion of publications showing null results.

It would be helpful if future studies included more elaborate descriptive statistics and a sequence of basic associations that can be compared across studies. Online supplements and replication packages provide an excellent opportunity for including this information. At a minimum, the basic persistence in social status across more than two generations should be described. This is valuable information. Insofar as these estimates continue to diverge from what extrapolating from two generations leads us to expect, they serve to motivate continued investigation into the sources of this previously hidden persistence in social status. 


\section{Notes}

1 We are also very grateful to Guido Neidhöfer, who kindly shared with us the results of his search of the literature.

2 In fact there is a third, occurring only once: Stuhler's (2014:23) fullest model includes a control for father's cognitive ability, which reduces the sample size to 2,789 from 47,797 in the previous model excluding the control. The model excluding this control is used. This does not affect whether a grandparent effect is found.

3 We accessed a version of this article dated March 20, 2017, sent to us directly by the authors. For the purposes of Figure 1 the article is dated 2017. A publicly accessible version (dated November 22, 2016) with identical results to those referred to in our article is available at the following link, last accessed by us on February 5th, 2018: https://www. econstor.eu/bitstream/10419/148300/1/870606824.pdf.

\section{References}

Adermon, Adrian, Mikael Lindahl, and Mårten Palme. 2016. "Dynastic Human Capital, Inequality and Intergenerational Mobility." Working Paper, Institute for Evaluation of Labour Market and Education Policy, Uppsala, Sweden. Retrieved July 13, 2017. https://www.ifau.se/globalassets/pdf/se/2016/ wp2016-19-dynastic-human-capital-inequality-and-intergenerational-mobility . pdf.

Becker, Gary S., and Nigel Tomes. 1986. "Human Capital and the Rise and Fall of Families." Journal of Labor Economics 4(3, pt 2):S1-S39. https : //doi . org/10 . 1086/298118.

Behrman, Jere, and Paul Taubman. 1985. "Intergenerational Earnings Mobility in the United States: Some Estimates and a Test of Becker's Intergenerational Endowments Model." The Review of Economics and Statistics 67(1):144-51. https : //doi .org/10 . 2307/1928446.

Bengtson, Vern L. 2001. "Beyond the Nuclear Family: The Increasing Importance of Multigenerational Bonds." Journal of Marriage and Family 63(1):1-16. https://doi.org/10. $2307 / 1928446$.

Black, Sandra E., Paul J. Devereux, and Kjell G. Salvanes. 2005. "The More the Merrier? The Effect of Family Size and Birth Order on Children's Education." Quarterly Journal of Economics 120(2):669-700.

Bol, Thijs, and Matthijs Kalmijn. 2016. "Grandparents' Resources and Grandchildren's Schooling: Does Grandparental Involvement Moderate the Grandparent Effect?" Social Science Research 55:155-70. https://doi .org/10.1016/j . ssresearch. 2015.09.011.

Braun, Sebastian Till, and Jan Stuhler. 2017. "The Transmission of Inequality Across Multiple Generations: Testing Recent Theories with Evidence from Germany." The Economic Journal, first published on July 31, 2017 as doi:10.1111/ecoj.12453.

Celhay, Pablo, and Sebastián Gallegos. 2015. "Persistence in the Transmission of Education: Evidence across Three Generations for Chile." Journal of Human Development and Capabilities 16(3):420-51. https://doi .org/10.1080/19452829.2015.1048789.

Chan, Tak Wing, and Vikki Boliver. 2013. "The Grandparents Effect in Social Mobility: Evidence from British Birth Cohort Studies." American Sociological Review 78(4):662-78. https://doi.org/10.1177/0003122413489130.

Chiang, Yi-Lin, and Hyunjoon Park. 2015. "Do Grandparents Matter? A Multigenerational Perspective on Educational Attainment in Taiwan." Social Science Research 51:163-73. https://doi.org/10.1016/j.ssresearch.2014.09.013. 
Clark, Gregory. 2014. The Son Also Rises: Surnames and the History of Social Mobility. Princeton, NJ: Princeton University Press.

Daw, Jonathan, and S. Michael Gaddis. 2016. "Education in 3G: Heterogeneity of Intergenerational Educational Mobility in the U.S." Social Science Research Network. Retrieved March 9, 2017. https : //papers . ssrn. com/abstract=2710883.

Deindl, Christian, and Nicole Tieben. 2016. "Resources of Grandparents: Educational Outcomes Across Three Generations in Europe and Israel." Journal of Marriage and Family 79(3):769-83. https://doi.org/10.1111/jomf . 12382.

Dribe, Martin, and Jonas Helgertz. 2016. "The Lasting Impact of Grandfathers: Class, Occupational Status, and Earnings over Three Generations in Sweden 1815-2011." The Journal of Economic History 76(4):969-1000. https : //doi .org/10.1017/S0022050716000991.

Ferguson, Jason L., and Douglas D. Ready. 2011. "Expanding Notions of Social Reproduction: Grandparents' Educational Attainment and Grandchildren's Cognitive Skills." Early Childhood Research Quarterly 26(2):216-26. https : //doi .org/10.1016/j . ecresq. 2010. 10.001.

Ferrie, Joseph, Catherine Massey, and Jonathan Rothbaum. 2016. "Do Grandparents and Great-Grandparents Matter? Multigenerational Mobility in the US, 1910-2013." National Bureau of Economic Research, Working Paper Series, Working Paper 22635. Retrieved April 14, 2017. http://www.nber .org/papers/w22635.

Grant, Elizabeth. 2005. "Cumulative Advantage: A New Look at the Effect of Family Social Class on Children's Educational Achievement and the Black-White Achievement Gap." PhD thesis, Stanford University. Retrieved July 7, 2017. https: //search . proquest . com/ docview/305436426/abstract/E08D1FBE267C4B3CPQ/1.

Hällsten, Martin. 2014. "Inequality across Three and Four Generations in Egalitarian Sweden: 1st and 2nd Cousin Correlations in Socio-Economic Outcomes." Research in Social Stratification and Mobility 35:19-33. https://doi .org/10.1016/j.rssm.2013.09.002.

Hällsten, Martin, and Fabian T. Pfeffer. 2017. "Grand Advantage: Family Wealth and Grandchildren's Educational Achievement in Sweden." American Sociological Review 82(2):328-60. https://doi.org/10.1177/0003122417695791.

Hancock, Kirsten, Francis Mitrou, Jenny Povey, Alice Campbell, and Stephen Zubrick. 2016. "Three-Generation Education Patterns among Grandparents, Parents and Grandchildren: Evidence of Grandparent Effects from Australia." Working Paper, University of Queensland. Retrieved April 12, 2017. https : //espace. library .uq. edu . au/view/UQ : 386329.

Havari, Enkelejda, and Marco Savegnago. 2012. "Intergenerational Transmission of Human Capital. Evidence from a Three Generation Study." Working Paper, Retrieved April 12, 2017. http://www.webmeets.com/files/papers/res/2013/998/Havari_Savegnago_ 2012 .pdf.

Hertel, Florian R., and Olaf Groh-Samberg. 2014. "Class Mobility across Three Generations in the U.S. and Germany." Research in Social Stratification and Mobility 35:35-52. https : //doi.org/10.1016/j.rssm.2013.09.007.

Hill, M. Anne, and June O'Neill. 1994. "Family Endowments and the Achievement of Young Children with Special Reference to the Underclass." Journal of Human Resources 29(4):1064-100. https://doi.org/10.2307/146134.

Jæger, Mads Meier. 2012. "The Extended Family and Children's Educational Success." American Sociological Review 77(6):903-22. https ://doi.org/10.1177/0003122412464040.

Knigge, Antonie. 2016. "Beyond the Parental Generation: The Influence of Grandfathers and Great-Grandfathers on Status Attainment." Demography 53(4):1219-44. https://doi . org/10.1007/s13524-016-0486-6. 
Kolk, Martin. 2014. "Multigenerational Transmission of Family Size in Contemporary Sweden." Population Studies 68(1):111-29. https://doi.org/10.1080/00324728.2013. 819112.

Kroeger, Sarah, and Owen Thompson. 2016. "Educational Mobility across Three Generations of American Women." Economics of Education Review 53:72-86. https://doi.org/10. 1016/j. econedurev. 2016.05.003.

Lindahl, Mikael, Mårten Palme, Sofia Sandgren Massih, and Anna Sjögren. 2015. "LongTerm Intergenerational Persistence of Human Capital: An Empirical Analysis of Four Generations." Journal of Human Resources 50(1):1-33. https://doi .org/10.3368/jhr. 50.1 .1$.

Lindahl, Mikael, Mårten Palme, Sofia Sandgren-Massih, and Anna Sjögren. 2014. "A Test of the Becker-Tomes Model of Human Capital Transmission Using Microdata on Four Generations." Journal of Human Capital 8(1):80-96. https : //doi .org/10 . 1086/674104.

Loury, Linda Datcher. 2006. "All in the Extended Family: Effects of Grandparents, Aunts, and Uncles on Educational Attainment." The American Economic Review 96(2):275-78. https://doi.org/10.1257/000282806777212099.

Loury, Linda Datcher. 2010. "College Schooling for Grandchildren and Contact with Grandparents." Working Paper, Department of Economics, Tufts University. Retrieved July 2, 2017. https://ideas.repec.org/p/tuf/tuftec/0757.html.

Mare, Robert D. 2011. "A Multigenerational View of Inequality." Demography 48(1):1-23. https://doi.org/10.1007/s13524-011-0014-7.

Mason, Jennifer, Vanessa May, and Lynda Clarke. 2007. "Ambivalence and the Paradoxes of Grandparenting." The Sociological Review 55(4):687-706. https://doi .org/10.1111/j . 1467-954X . 2007.00748.x.

Modin, Bitte, Robert Erikson, and Denny Vågerö. 2013. "Intergenerational Continuity in School Performance: Do Grandparents Matter?" European Sociological Review 29(4):858-70. https://doi.org/10.1093/esr/jcs064.

Modin, Bitte, and Johan Fritzell. 2009. "The Long Arm of the Family: Are Parental and Grandparental Earnings Related to Young Men's Body Mass Index and Cognitive Ability?" International Journal of Epidemiology 38(3):733-44. https ://doi .org/10.1093/i je/dyp001.

Møllegaard, Stine, and Mads Meier Jæger. 2015. "The Effect of Grandparents' Economic, Cultural, and Social Capital on Grandchildren's Educational Success." Research in Social Stratification and Mobility 42:11-19. https://doi .org/10.1016/j.rssm.2015.06.004.

Mukherjee, Ramkrishna. 1954. "Social Mobility Between Three Generations." Pp. 266-90 in Social Mobility in Britain, edited by D. V. Glass. London: Routledge and Kegan Paul Limited.

Neidhöfer, Guido, and Maximilian Stockhausen. Forthcoming. "Dynastic Inequality Compared: Multigenerational Mobility in the US, the UK, and Germany." Review of Income and Wealth.

Pfeffer, Fabian T. 2014. "Multigenerational Approaches to Social Mobility. A Multifaceted Research Agenda." Research in Social Stratification and Mobility 35:1-12. https://doi. org/10.1016/j.rssm.2014.01.001.

Pfeffer, Fabian T., and Alexandra Killewald. 2017. "Generations of Advantage. Multigenerational Correlations in Family Wealth." Social Forces, first published on December 13, 2017 as doi:10.1093/sf/sox086.

Phillips, Meredith, Jeanne Brooks-Gunn, Greg J. Duncan, Pamela Klebanov, and Jonathan Crane. 1998. "Family Background, Parenting Practices, and the Black-White Test Score 
Gap." Pp. 102-45 in The Black-White Test Score Gap, edited by C. Jencks and M. Phillips. Washington, D.C.: Brookings Institution Press.

Piraino, Patrizio, Sean Muller, Jeanne Cilliers, and Johan Fourie. 2014. "The Transmission of Longevity across Generations: The Case of the Settler Cape Colony." Research in Social Stratification and Mobility 35:105-19. https: //doi.org/10.1016/j.rssm. 2013.08.005.

Prix, Irene, and Fabian T. Pfeffer. 2017. "Does Donald Need Uncle Scrooge? Extended Family Wealth and Children's Educational Attainment in the United States." Pp. 112-35 in Social Inequality Across the Generations: The Role of Compensation and Multiplication in Resource Accumulation, edited by J. Erola and E. Kilpi-Jakonen. Cheltenham, England: Edward Elgar Publishing Limited. https://doi .org/10.4337/9781786432568.00013.

Robins, James M., Miguel Ángel Hernán, and Babette Brumback. 2000. "Marginal Structural Models and Causal Inference in Epidemiology." Epidemiology 11(5):550-60. https ://doi . org/10.1097/00001648-200009000-00011.

Sauder, Ulrich. 2006. "Education Transmission across Three Generations - New Evidence from NCDS Data." Working Paper, University of Warwick. Retrieved April 12, 2017. http://www.hec.unil.ch/deep/evenements/Brownbag-papers/2006-07/ Sauder-nov06.pdf.

Sharkey, Patrick, and Felix Elwert. 2011. "The Legacy of Disadvantage: Multigenerational Neighborhood Effects on Cognitive Ability." American Journal of Sociology 116(6):1934-81. https://doi.org/10.1086/660009.

Sheppard, Paula, and Christiaan W. S. Monden. 2017. "The Additive Advantage of Having Educated Grandfathers for Children's Education: Evidence from a Cross-National Sample in Europe." Paper presented at the Multi-Generational Mobility Workshop, September 21-22, 2017, Nuffield College, University of Oxford, Oxford, UK. Retrieved January 25, 2018. https://osf.io/sw4z9/.

Song, Xi. 2016. "Diverging Mobility Trajectories: Grandparent Effects on Educational Attainment in One- and Two-Parent Families in the United States." Demography 53(6):190532. https://doi.org/10.1007/s13524-016-0515-5.

Song, Xi, and Cameron D. Campbell. 2017. "Genealogical Microdata and Their Significance for Social Science." Annual Review of Sociology 43:75-99. https://doi.org/10.1146/ annurev-soc-073014-112157.

Stuhler, Jan. 2014. "Mobility Across Multiple Generations: The Iterated Regression Fallacy." Working Paper, University College London. Retrieved December 13, 2016. http://www.homepages.ucl.ac.uk/ uctpjst/stuhler_mobility_across_ multiple_generations .pdf.

Warren, John Robert, and Robert M. Hauser. 1995. "Social Stratification Across Three Generations: New Evidence From the Wisconsin Longitudinal Study." Working Paper, Center for Demography and Ecology, University of Wisconsin-Madison. Retrieved March 31, 2017. https://www.ssc.wisc. edu/cde/cdewp/95-05.pdf.

Wightman, Patrick, and Sheldon Danziger. 2014. "Multi-Generational Income Disadvantage and the Educational Attainment of Young Adults." Research in Social Stratification and Mobility 35:53-69. https://doi .org/10.1016/j.rssm. 2013.09.004.

Wolbers, Maarten H. J., and Wout C. Ultee. 2013. "Driegeneraties- en tweeoudersvragen over het opleidingsniveau van mannen en vrouwen in Nederland [Three Generations and Two Parents Questions about the Level of Education of Men and Women in the Netherlands]." Mens \& Maatschappij 88(3):276-99. https://doi .org/10.5117/MEM2013.3. WOLB. 
Yeung, W. Jean, and Dalton Conley. 2008. "Black-White Achievement Gap and Family Wealth." Child Development 79(2):303-24. https://doi.org/10.1111/j.1467-8624. $2007.01127 . x$.

Zeng, Zhen, and Yu Xie. 2014. "The Effects of Grandparents on Children's Schooling: Evidence From Rural China." Demography 51(2):599-617. https://doi .org/10.1007/ s13524-013-0275-4.

Ziefle, Andrea. 2016. "Persistent Educational Advantage Across Three Generations: Empirical Evidence for Germany." Sociological Science 3:1077-102. https ://doi .org/10 .15195/ v3. a47.

Acknowledgements: We are grateful to Patrick Präg for his many useful comments and suggestions, to Guido Neidhöfer for sharing with us the results of his literature search, and to the participants of the Multigenerational Social Mobility Workshop held at Nuffield College, University of Oxford on September 21 and 22, 2017, for their comments. This research has received funding from the European Research Council under the European Union's Horizon 2020 research and innovation program under grant agreement number 681546 (FAMSIZEMATTERS).

Lewis R. Anderson: Trinity College and Department of Sociology, University of Oxford. E-mail: lewis.anderson@sociology.ox.ac.uk.

Paula Sheppard: Nuffield College and Department of Sociology, University of Oxford. E-mail: paula.sheppard@sociology.ox.ac.uk.

Christiaan W. S. Monden: Nuffield College and Department of Sociology, University of Oxford.

E-mail: christiaan.monden@sociology.ox.ac.uk. 